Research Article

\title{
Cardioprotective effect of Solanum nigrum against doxorubicin induced cardiotoxicity-an experimental study
}

\author{
Privy Varshney ${ }^{1}$, Pinki Vishwakarma ${ }^{1}$, Monica Sharma ${ }^{1}$, Manish Saini ${ }^{1}$, \\ Shaily Bhatt ${ }^{1}$, Ganesh Singh ${ }^{2}$, K.K. Saxena ${ }^{1}$
}

\begin{abstract}
${ }^{1}$ Department of Pharmacology, ${ }^{2}$ Department of Community Medicine, L.L.R.M Medical College, Meerut. Uttar Pradesh, India,
\end{abstract}

Received: 17 February 2016 Accepted: 21 March 2016

*Correspondence to: Dr. Privy Varshney, Email: privyvarshney @gmail.com

Copyright: (C) the author(s), publisher and licensee Medip Academy. This is an openaccess article distributed under the terms of the Creative Commons Attribution NonCommercial License, which permits unrestricted noncommercial use, distribution, and reproduction in any medium, provided the original work is properly cited.

\begin{abstract}
Background: Solanum nigrum (S.nigrum) a medicinal herb is widely used in the Indian system of medicine for treatment of various ailments. The methanolic extract of S.nigrum berries had shown cardio protective and antioxidant effect. However, so far aqueous extract of S.nigrum is not scientifically evaluated for its cardio protective potential. Hence the present study was designed to find out cardio protective role of S.nigrum against doxorubicin induced cardiotoxicity. Methods: Seventy two rats were randomized into four major groups $(n=6)$. group I received $2 \mathrm{ml} / 100 \mathrm{~g} /$ day normal saline p.o daily, group II received 2 $\mathrm{ml} / 100 \mathrm{~g} /$ day of normal saline p.o daily, group III received carvedilol 30 $\mathrm{mg} / \mathrm{kg} /$ day p.o daily and group IV received S.nigrum $1 \mathrm{~g} / \mathrm{kg} /$ day p.o daily for test durations of 20, 30 and 40 days respectively. Doxorubicin $20 \mathrm{mg} / \mathrm{kg}$ i.p single dose was given to induce cardiotoxicity in rats of group II, III and IV respectively on last day of each experiment. Animals were sacrificed 48 hours after doxorubicin administration. Cardiac serum markers creatinine phosphokinase MB, lactate dehydrogenase, serum glutamate oxaloacetate transaminase and serum glutamate pyruvate transaminase were analysed biochemically. Histopathological changes were studied under light microscope. Results: All cardiac serum marker levels were found significantly $(\mathrm{p}<0.001)$ increased in doxorubicin group while S.nigrum pretreated group displayed significant $(\mathrm{p}<0.001)$ reduction in rise of these parameters in a time dependent manner indicating cardio protection. Histological observations further correlated the cardio protective effect of S.nigrum.

Conclusions: The present study concluded that aqueous extract of S.nigrum possess cardio protective potential against doxorubicin induced cardiotoxicity.
\end{abstract}

Keywords: Cardio toxicity, Carvedilol, Doxorubicin, Solanum nigrum

\section{INTRODUCTION}

New anticancer agents and targeted therapies have led to a long life expectancy in cancer patients. However, many of these treatments can cause devastating complications such as heart failure, cardiomyopathy etc, in cancer treated patients. ${ }^{1}$ Cardio toxicity of anticancer drugs is a very significant problem, especially with anthracycline group (doxorubicin) and is the leading cause of morbidity in cancer patients. Other cytotoxic drugs such as 5-flurouracil, cyclophosphamide and taxoids are also associated with cardio toxicity, although their mechanism of cardio toxicity is not totally revealed. ${ }^{2}$ Doxorubicin induced formation of reactive oxygen species (ROS) leads to oxidative stress, that results in impaired mitochondrial function, cellular membrane damage and cytotoxicity. ${ }^{3}$ Many agents from modern therapeutic armamentarium have been investigated for their potential to afford cardiac protection. But these agents have not been able to come up with a satisfactory answer, against the menace of cardio toxicity caused by drugs which are essentially prescribed for malignancies and other ailments. 
Carvedilol, a non- selective $\beta$-blocker, had been shown to possess cardio protective effect against Doxorubicin induced cardio toxicity, that can be attributed to its antioxidant property and not to its $\beta$-blocking property. ${ }^{4}$ In present study carvedilol served as standard drug.

Solanum nigrum (S.nigrum) belongs to family solanaceae. Commonly known as "black night shade" or "makoy". It has been traditionally used to treat various ailments such as pain, inflammation, fever and enteric diseases. $^{5}$ It elaborates a wide spectrum of pharmacological properties such as anti-inflammatory, anti-cancer, anti-seizure, antioxidant activity, hepato protective activity, and cardio protective activity. ${ }^{6-11}$ The paucity of information on cardio protective properties of S.nigrum in experimental animals has necessitated the design of present study with aim of providing scientific information on the effects of S.nigrum on doxorubicin induced cardio toxicity in rats.

\section{METHODS}

\section{Animals}

Seventy two adult wistar albino rats of either sex weighing 150-200 g ( $n=6$ in each group) were obtained from rat rearing unit of central animal house of the Institute. The selected rats were housed in cages under controlled conditions of temperature $\left(25^{\circ} \mathrm{C}\right)$ and 12 hour light/dark cycle. The animals had free access to standard rat pellet diet and tap water ad libitum. The study was approved by the IAEC (approval letter no. IAEC/2015/1).

\section{Preparation of plant extract}

The S.nigrum plant was collected, carefully segregated, washed and dried in shade. The dried stem and leaves were powered mechanically with an electric grinder. Then $50 \mathrm{~g}$ of this powder was immersed in $750 \mathrm{ml}$ of distilled water. This solution was slowly heated to $100^{\circ} \mathrm{C}$ for a period of 50 minutes and then followed by another one hour at $100^{\circ} \mathrm{C}$. The aqueous extract was further condensed into a final concentration of $1 \mathrm{~g} / \mathrm{ml}$.

\section{Drugs and chemicals}

Doxorubicin hydrochloride (Zubidox) was purchased from Adley formulations Pvt Ltd, India. Carvedilol (Carca) was purchased from Intas pharmaceutical Pvt. Ltd, India. CKMB and LDH test assay kits were procured from Melrose Healthcare Pvt Ltd, India. SGOT and SGPT test assay kit were procured from ELI Tech clinical system, France.

\section{Experimental study design}

Seventy two rats were randomized into four major groups of six animals each. Group I served as control group (CT), group II was doxorubicin (DOX), group III (CARVE) was given carvedilol and group IV was
S. nigrum (SN) group. All these groups were studied for 20, 30 and 40 days duration. Drugs were administered as following;

\section{Group I}

Normal saline (2 ml/100 g/day p.o daily).

\section{Group II}

Normal saline $(2 \mathrm{ml} / 100 \mathrm{~g} /$ day p.o daily)+doxorubicin (20 mg/kg i.p single dose on $20^{\text {th }}, 30^{\text {th }}$ and $40^{\text {th }}$ day of experiment).

\section{Group III}

Carvedilol (30 mg/kg/day p.o daily)+doxorubicin (20 $\mathrm{mg} / \mathrm{kg}$ i.p single dose on $20^{\text {th }}, 30^{\text {th }}$ and $40^{\text {th }}$ day of experiment).

\section{Group IV}

Solanum nigrum ( $1 \mathrm{~g} / \mathrm{kg} /$ day p.o daily)+doxorubicin (20 $\mathrm{mg} / \mathrm{kg}$ i.p single dose on $20^{\text {th }}, 30^{\text {th }}$ and $40^{\text {th }}$ day of experiment).

After doxorubicin administration on $20^{\text {th }}, 30^{\text {th }}$ and $40^{\text {th }}$ day, rats of all the groups were fasted for 48 hours, during which tap water remained freely available and then rats were sacrificed using diazepam $(10 \mathrm{mg} / \mathrm{kg}$ i.p. $)$ and ketamine (75 mg/kg i.p.) anaesthesia. ${ }^{12} 5 \mathrm{ml}$ of blood sample was collected from abdominal aorta of anaesthetized animal. After blood collection cardiac tissue was dissected out for histopathological examination at the end of every test duration study.

\section{Serum markers}

Cardiac serum markers creatinine phosphokinase MB (CKMB), lactate dehydrogenase (LDH), serum glutamate oxaloacetate transaminase (SGOT) and serum glutamate pyruvate transaminase (SGPT) were analysed using assay kits on the $22^{\text {nd }}, 32^{\text {nd }}$ and $42^{\text {nd }}$ day of the test duration respectively.

\section{Histopathology}

At the end of experiment for all the test durations the rat heart was excised and washed with normal saline. Whole of the heart was placed in 10\% neutral formalin for 12-24 hours. It was then dehydrated and cleared with ethanol and xylene respectively; blocks were prepared after embedding it in paraffin wax. From these blocks sections of $5 \mu \mathrm{m}$ thickness were made using microtome and were stained with Harris haematoxylin and Eosin stain and then subjected for histopathological examination under light microscope. ${ }^{13,14}$ 


\section{Statistical analysis}

Descriptive statistics mean and standard error were calculated for all variables of each group to observe the general trend of the group. The statistical analysis was carried out using one-way Analysis of variance (ANOVA) with post-hoc analysis. P-value was estimated using SPSS software. P-value $<0.05$ has been considered as statistically significant.

\section{RESULTS}

Serum enzyme levels, depicted in (Table 1-3), the mean CKMB level (IU/L) in normal saline treated group ranged from $499.67 \pm 15.09$ to $509.83 \pm 10.60$ in all test durations. There is a significant increase in CKMB serum markers level in doxorubicin treated Group II rats as compared to group I (CT) in all the test durations of 20, 30 and 40 days as $999.17 \pm 20.51, \quad 1019.67 \pm 34.29$ and $1009.17 \pm 26.87$ respectively (Table 1-3). The group III (CARVE) rats showed significant $(p<0.01)$ decrease in CKMB levels when compared to group II (DOX).

Administration of aqueous extract of S.nigrum in Group IV exhibited time dependent limitation of CKMB rise after DOX administration for 20,30 and 40 days as $856.50 \pm 15.87, \quad 812.17 \pm 26.20$ and $790.17 \pm 11.44$ respectively (Table 1-3).

A highly significant $(\mathrm{p}<0.001)$ rise in serum LDH levels was seen in doxorubicin treated group II as compared to the normal saline treated group I. The effect of S. nigrum pre-treatment on serum LDH levels exhibit a trend similar to that seen in case of CKMB (Table 1-3).

Table 1: Effect of Carvedilol ( $30 \mathrm{mg} / \mathrm{kg}$ p.o daily) and solanum nigrum (1 g/kg p.o daily) for the duration of 20 days.

\begin{tabular}{|llllll|}
$\begin{array}{l}\text { Group } \\
(\mathbf{n}=6)\end{array}$ & Treatment & $\begin{array}{l}\text { CKMB (IU/L) } \\
\text { Mean } \pm \text { SE }\end{array}$ & $\begin{array}{l}\text { LDH (IU/L) } \\
\text { Mean } \pm \text { SE }\end{array}$ & $\begin{array}{l}\text { SGOT (IU/L) } \\
\text { Mean } \pm \text { SE }\end{array}$ & $\begin{array}{l}\text { SGPT (IU/L) } \\
\text { Mean } \pm \text { SE }\end{array}$ \\
\hline Group I & Control (CT) & $509.83 \pm 10.60$ & $755.67 \pm 15.43$ & $116.50 \pm 2.89$ & $63.67 \pm 2.70$ \\
\hline Group II & $\begin{array}{l}\text { Doxorubicin (DOX) } \\
\text { on } 20^{\text {th }} \text { day }\end{array}$ & $999.17 \pm 20.51^{@}$ & $1286.67 \pm 30.61^{\circledR}$ & $206.67 \pm 7.68^{@}$ & $164 \pm 2.82^{@}$ \\
\hline Group III & $\begin{array}{l}\text { Carvedilol (CARVE)+DOX on } \\
20^{\text {th }} \text { day }\end{array}$ & $699 \pm 12.29^{*}$ & $874.83 \pm 13.27^{*}$ & $152.33 \pm 3.11^{*}$ & $85.50 \pm 2.21^{*}$ \\
\hline Group IV & $\begin{array}{l}\text { S.Nigrum (SN)+DOX on } 20^{\text {th }} \\
\text { day }\end{array}$ & $856.50 \pm 15.87^{\# \mu}$ & $1012 \pm 5.69^{\# \mu}$ & $170.67 \pm 3.87^{\# \alpha}$ & $113.33 \pm 5.38^{\# \mu}$ \\
\hline
\end{tabular}

$@ \mathrm{p}<0.001$ when compared to control, *p $<0.001$ when compared to DOX, \# $\mathrm{p}<0.001$ when compared to DOX, $\mu \mathrm{p}<0.001$ when compared to carvedilol. $\alpha \mathrm{p}=0.012$ when compared to carvedilol.

Table 2: Effect of Carvedilol (30 mg/kg p.o daily) and solanum nigrum ( $1 \mathrm{~g} / \mathrm{kg}$ p.o daily) for the duration of 30 days.

\begin{tabular}{|c|c|c|c|c|c|}
\hline $\begin{array}{l}\text { Group } \\
(\mathbf{n}=\mathbf{6})\end{array}$ & Treatment & $\begin{array}{l}\text { CKMB (IU/L) } \\
\text { Mean } \pm \text { SE }\end{array}$ & $\begin{array}{l}\text { LDH (IU/L) } \\
\text { Mean } \pm \text { SE }\end{array}$ & $\begin{array}{l}\text { SGOT }(\text { IU/L) } \\
\text { Mean } \pm \text { SE }\end{array}$ & $\begin{array}{l}\text { SGPT (IU/L) } \\
\text { Mean } \pm \text { SE }\end{array}$ \\
\hline Group I & Control (CT) & $501.17 \pm 11.20$ & $759.83 \pm 16.38$ & $121 \pm 2.81$ & $62.17 \pm 2.68$ \\
\hline Group II & Doxorubicin (DOX) on $30^{\text {th }}$ day & $1019.67 \pm 34.29^{@}$ & $1296.67 \pm 12.33^{\circledR}$ & $208.67 \pm 5.28^{@}$ & $158 \pm 2.73^{@}$ \\
\hline Group III & $\begin{array}{l}\text { Carvedilol (CARVE)+DOX on } 30^{\text {th }} \\
\text { day }\end{array}$ & $618.83 \pm 29.61 *$ & $764.50 \pm 13.62 *$ & $140.67 \pm 2.34 *$ & $69.97 \pm 3.07^{*}$ \\
\hline Group IV & S.Nigrum $(\mathrm{SN})+\mathrm{DOX}$ on $30^{\text {th }}$ day & $812.17 \pm 26.20^{\# \mu}$ & $974.83 \pm 8.61^{\# \mu}$ & $164.67 \pm 4.31^{\# \mu}$ & $108 \pm 3.23^{\# \mu}$ \\
\hline
\end{tabular}

Table 3: Effect of carvedilol (30 $\mathrm{mg} / \mathrm{kg}$ p.o daily) and solanum nigrum $(1 \mathrm{~g} / \mathrm{kg}$ p.o daily) for the duration of 40 days.

\begin{tabular}{|c|c|c|c|c|c|}
\hline $\begin{array}{l}\text { Group } \\
(\mathrm{n}=\mathbf{6})\end{array}$ & Treatment & $\begin{array}{l}\text { CKMB(IU/L) } \\
\text { Mean } \pm \text { SE }\end{array}$ & $\begin{array}{l}\text { LDH(IU/L) } \\
\text { Mean } \pm \text { SE }\end{array}$ & $\begin{array}{l}\text { SGOT(IU/L) } \\
\text { Mean } \pm \text { SE }\end{array}$ & $\begin{array}{l}\text { SGPT(IU/L) } \\
\text { Mean } \pm \text { SE }\end{array}$ \\
\hline Group I & Control (CT) & $499.67 \pm 15.09$ & $747 \pm 10.84$ & $118.50 \pm 2.77$ & $63.5 \pm 2.75$ \\
\hline Group II & Doxorubicin (DOX) on $40^{\text {th }}$ day & $1009.17 \pm 26.87^{@}$ & $1290.33 \pm 33.58^{@}$ & $207.67 \pm 6.31^{\Theta}$ & $163.33 \pm 3.60^{\Theta}$ \\
\hline Group III & $\begin{array}{l}\text { Carvedilol (CARVE)+DOX on } \\
40^{\text {th }} \text { day }\end{array}$ & $584.33 \pm 17.23 *$ & $735.67 \pm 19.20 *$ & $125 \pm 4.72 *$ & $64.67 \pm 2.40 *$ \\
\hline Group IV & S.Nigrum $(\mathrm{SN})+\mathrm{DOX}$ on $40^{\text {th }}$ day & $790.17 \pm 11.44^{\# \mu}$ & $940.17 \pm 17.02^{\# \mu}$ & $158 \pm 1.86^{\# \mu}$ & $93.50 \pm 3.63^{\# \mu}$ \\
\hline
\end{tabular}

$@ \mathrm{p}<0.001$ when compared to control, *p<0.001 when compared to DOX, \# $\mathrm{p}<0.001$ when compared to DOX, $\mu \mathrm{p}<0.001$ when

compared to carvedilol. 
The administration of DOX significantly increased $(p<0.001)$ the serum SGOT as compared to normal saline treated group. Carvedilol administration significantly reduced the rise in SGOT level $(\mathrm{p}<0.001)$. However, administration of S.nigrum for 20 days group was not found to be statistically significant compared to Carvedilol, while S.nigrum administration for 30 and 40 days significantly reduced rise in SGOT levels (Table 1-3).

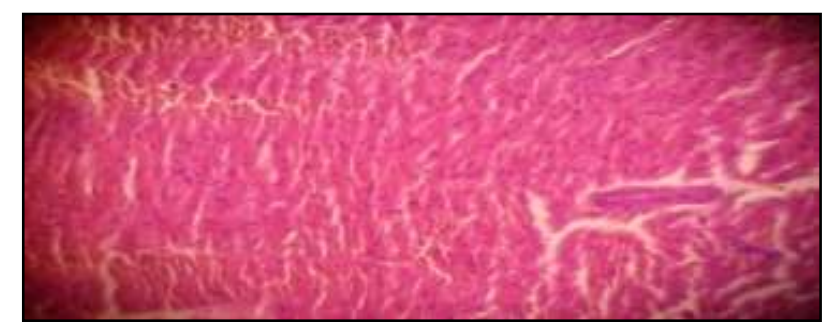

Figure 1: Microscopic features of rat heart treated with normal saline.

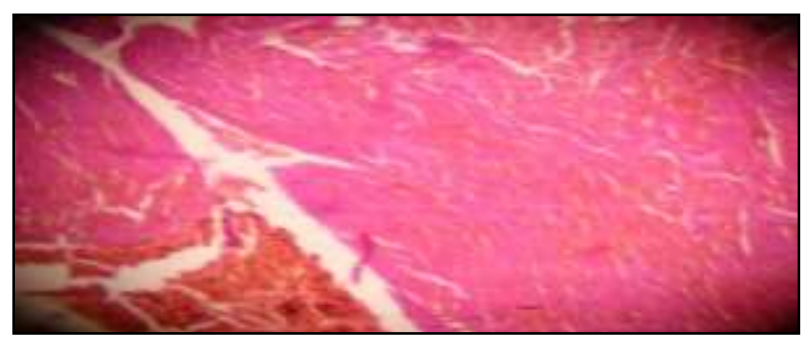

Figure 2: Microscopic features of rat heart treated with doxorubicin.

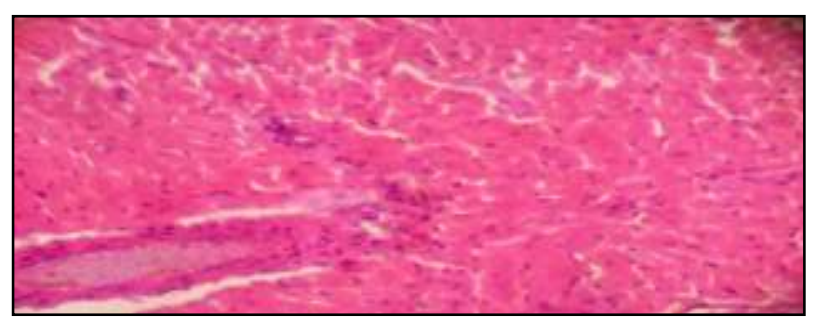

Figure 3: Microscopic features of rat heart treated with S.nigrum (1 g/kg/day p.o+DOX 20 mg/kg i.p single dose) for 20 days.

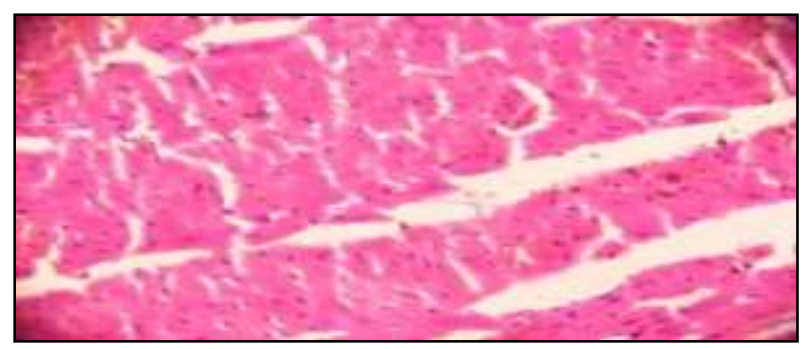

Figure 4: Microscopic features of rat heart treated with S.nigrum (1 g/kg/day p.o+DOX 20 mg/kg i.p single dose) for 30 days.

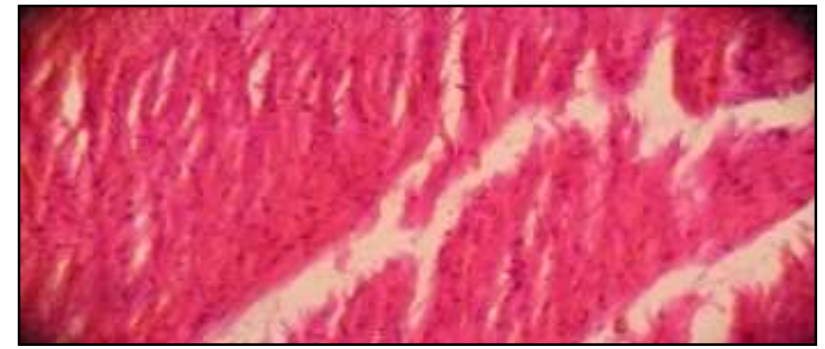

Figure 5: Microscopic features of rat heart treated with S.nigrum (1 g/kg/day p.o+DOX 20 mg/kg i.p single dose) for $\mathbf{4 0}$ days.

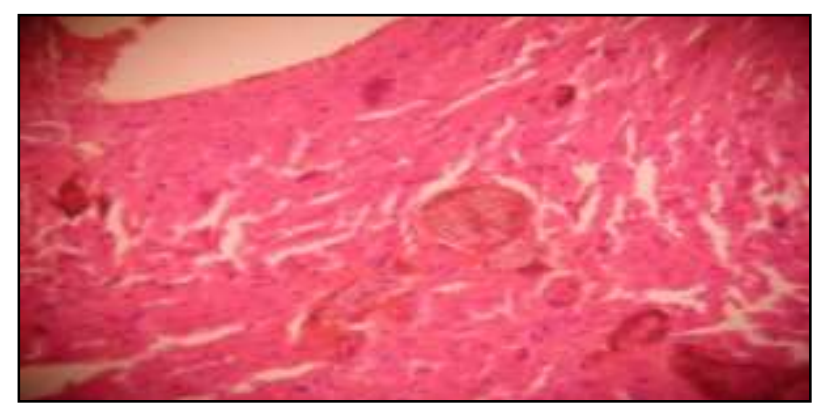

Figure 6: Microscopic features of rat heart treated with carvedilol (30mg/kg/day p.o+DOX $20 \mathrm{mg} / \mathrm{kg}$ i.p single dose) for 20 days.

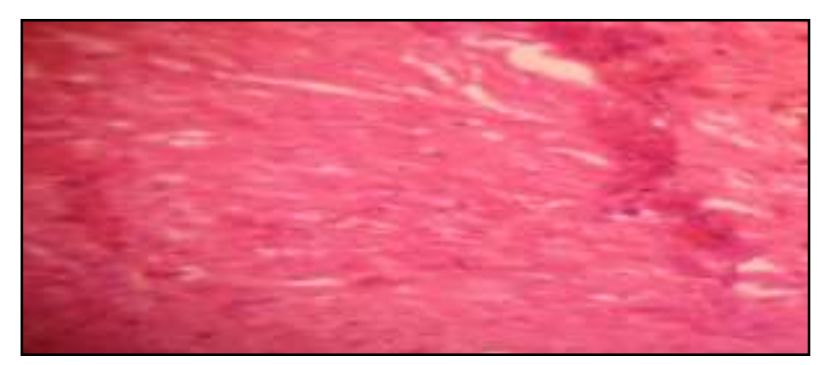

Figure 7: Microscopic features of rat heart treated with carvedilol (30 mg/kg/day p.o+DOX $20 \mathrm{mg} / \mathrm{kg}$ i.p single dose) for $\mathbf{3 0}$ days.

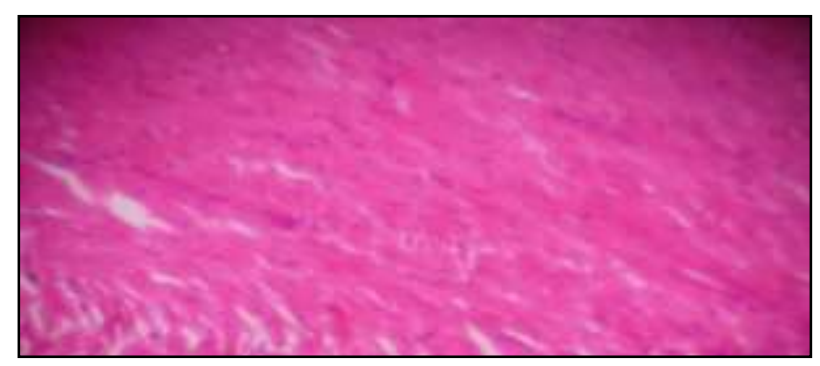

Figure 8: Microscopic features of rat heart treated with carvedilol $(30 \mathrm{mg} / \mathrm{kg} / \mathrm{day}$ p.o+DOX $20 \mathrm{mg} / \mathrm{kg}$ i.p single dose) for $\mathbf{4 0}$ days.

Pre-treatment with Carvedilol and S.nigrum significantly $(\mathrm{p}<0.001)$ reduced the rise in serum SGPT levels compared to doxorubicin treated group (Table 1-3). 


\section{Histopathological examination}

The histology of the heart tissue from rats of control group I and group III (CARVE) showed normal morphological appearances. While in group II (DOX) disruption, loss of myofibrils and vacuolization of the cytoplasm were observed. The histology of heart tissue from group IV (SN) showed less loss of my ibrils and degree of protection was evident clearly in a time dependent manner.

\section{DISCUSSION}

Throughout study it was apparent that doxorubicin administration produced cardio toxicity in rats as examined by serum markers raised levels and histopathological changes. Doxorubicin, a drug belonging to anthracycline group, is a highly effective antitumor drug but its usefulness is now very much limited because of the fact that it possess risk of developing cardiomyopathy. ${ }^{15}$ Excessive formation of free radicals and high level of oxidative stress produced by the DOX have been suggested to play an important role in promoting oxidative myocardial damage. ${ }^{16}$ Oxidative stress has been proposed to be a cause of development and progression of myocardial infarction and heart failure. ${ }^{17}$ The rat model of doxorubicin induced cardio toxicity has been widely used as a standard method to evaluate cardio protective drugs and to study myocardial consequences of ischemic disorders. ${ }^{18,19}$ DOX in a single dose of $20 \mathrm{mg} / \mathrm{kg}$ intra peritoneally has been utilized to induce cardio toxicity in other studies also. ${ }^{20}$

Carvedilol, a non-selective beta blocker has been used as a reliable cardioprotective agent by previous researchers ${ }^{21}$ and in the present study carvedilol served as a standard cardio protective drug. S.nigrum contain flavinoids such as naringenin that has been found to have cardio protective potential against DOX induced cardio toxicity on wistar rats. ${ }^{22,23}$ Myocardium contains an abundant amount of diagnostic marker enzymes for cardiotoxicity and once metabolically damaged, it releases its intracellular contents into the extracellular fluid, so that level of enzyme markers in serum reflects the alteration in membrane integrity and/or permeability. ${ }^{24}$ Cytosolic enzymes CKMB, LDH, SGOT and SGPT which also serve as the diagnostic markers in the study, leak out from the damaged tissue to the blood stream when cell membrane becomes permeable or ruptured. ${ }^{25}$ Results of the present study indicate that administration of DOX (20 $\mathrm{mg} / \mathrm{kg}$ i.p) elevated serum levels of cardiac bio markers similarly signify the myocardial damage similar to the studies done by Farvin et al. ${ }^{26}$ This rise of serum markers was found to be statistically significant in our study also. LDH rises within 24-48 hours after a heart attack and peaks in 2-3 days in serum. ${ }^{27}$ Consistent with the above clinical observation, in the present study we observed a significant rise in LDH levels of rats treated with DOX after 48 hours. S.nigrum pre-treatment significantly reduced the elevated LDH enzyme levels indicating the reduction in the severity of cardiac injury. Rise in SGOT levels has been previously reported to rise even if $10 \%$ of total myocardium damage occur and show linearity in rise with the amount of myocardial infarction. ${ }^{28}$

S. nigrum and carvedilol pre-treatment limited the rise in diagnostic enzyme marker level after DOX administration. It demonstrates that S.nigrum could maintain membrane integrity thereby restricting the leakage of these enzymes as that with carvedilol pretreatment. The results of the serum markers correlated with the histopathological observations in the myocardial tissues of animals treated with either DOX or test drugs or normal saline. The myocardial tissue in normal saline rats illustrated clear integrity of the myocardial cell membrane and absence of inflammatory cells infiltrations (Figure 1). DOX injected rats showed separation of cardiac muscle fibers and infiltration of inflammatory cells (Figure 2). The reduced inflammatory cell infiltration and normal cardiac muscle fibres architecture in S.nigrum treated rats further confirmed its cardio protective effect (Figure 2-4). In present study, DOX induced rise of serum markers was significantly decreased by the pre-treatment of $S$. nigrum in all test durations in a time dependent manner and the maximum cardio protective features were seen with 40 days pre-treatment, which were comparable to the standard drug, Carvedilol. The study reveals cardioprotective action of aqueous extract of S.nigrum, which could be attributed to synergetic effect of various antioxidant phyto-chemicals, present in it.

\section{CONCLUSION}

It was concluded from the present study that S.nigrum possesses cardio protective activity. These findings might prove to be helpful to understand the beneficial effects of S.nigrum against myocardial injury. However, an extended study using large number of animals with removal of confounding factors like pre-treatment cardiac enzyme marker levels, sequential administration of DOX and subsequent analysis is required so that substantial data can be generated for facilitating further evaluation of these agents through clinical trials. Further molecular level of investigation could be done using different animal models and other biochemical parameters to elucidate the possible mechanism of actions of S.nigrum.

\section{ACKNOWLEDGEMENTS}

Authors thankful to Dr Rajiv Nehra (Assistant Professor, Department of Biochemistry), Dr Preeti Singh (Assistant Professor, Department of Pathology), Dr Abhinav David ( Lecturer, Department of Pharmacology) L.L.R.M Medical College, Meerut, U.P. for their cooperation and sincere help in this study.

Funding: No funding sources Conflict of interest: None declared

Ethical approval: The study was approved by the Institutional Ethics Committee 


\section{REFERENCES}

1. Bovelli D, Plataniotis G, Roila F. Cardiotoxicity of chemotherapeutic agents and radiotherapy-related heart disease: ESMO Clinical practice Guidelines Annals of Oncology 21. 2010;5:277-82.

2. Schimmel KJ, Richel DJ, Van Den Brink RB, Guchelar HJ. Cardiotoxicity of cytotoxic drugs. Cancer Treat Rev. 2004;30:181-91.

3. Ky B, Vejpongsa P, Yeh ET, Force T, Moslehi JJ. Emerging paradigms in cardiomyopathies associated with cancer therapies. Circ Res. 2013;113:754-64.

4. Matsui H, Morishima I, Numaguchi Y, Toki Y, Okumura K, Hayakawa $\mathrm{T}$. protective effects of Carvedilol against doxorubicin-induced cardiomyopathy. Life Sci. 1999;65(2):1265-274.

5. Atanu FO, Ebiloma UG, Ajayi EI. A review of the pharmacological aspects of Solanum nigrum Linn. Biotechnology and Molecular Biology Review. 2011;6(1):001-7.

6. Ravi V, Saleem TSM, Patel SS, Raamamurthy J Gauthaman K. Anti-inflammatory effect of methanolic extract of solanum nigrum linn berries. International Journal of Applied Research in Natural Products. 2009;2(2):33-6.

7. Patels S, Gheewala N, Suthar A, Shah A. in-vitro cytotoxicity activity of solanum nigrum extracts against hela cell lines and vero cell lines. International Journal of Pharmacy and Pharmaceutical Sciences. 2009;1(1):38-46.

8. Wannang NN, Anuka JA, Kwanashe HO. Antiseizure activity of aqueous leaf extract of Solanum nigrum linn (solanaceae) in experimental animals. Afr Health Sci. 2008;8(2):74-9.

9. Lee SJ, Lim KT. Antioxidative effects of glycoprotein isolated from solanum nigrum linn. On oxygen radicals and its cytotoxic effects on the MCF7 cell. J Food Sci. 2003;68:466-70.

10. Kumar V, Sharma S, Modi PK. Exploration of hepatoprotective activity of aqueous extract of Solanum nigrum-an experimental study. IJPSR. 2013;4(1):464-70.

11. Bhatia N, Maiti PP, Kumar A, Tuli A, Ara T, Khan MU. Evaluation of cardio protective activity of methanolic extract of solanum nigrum linn. In rats. International Journal of Drug Development and Research. 2011;3(3):139-47.

12. Karwacki Z, Kowianski P, Morys J. General anaesthesia in rats undergoing experiments on the central nervous system: Folia Morphol. 2001;60(4):235-42.

13. Talib VH, editor. A handbook of medical laboratory technology. $2^{\text {nd }}$ ed. New Delhi: CBS Publisher and Distributors; 2007:155-167.

14. Clayden EC, editor. Practical section cutting and staining- part 1, London: Churchill Livingstone; 1971:1071.
15. Simunek T, Sterba M, Popelova O, Adamcova M, Hrdina R, Gers IV. Anthracycline-induced cardiotoxicity: overview of studies examining the roles of oxidative stress and free cellular iron.Pharmacol Rep. 2009;61:154-71.

16. Deavall DG, Martin EA, Horner JM, Roberts R. Drug-induced oxidative stress and toxicity. J. Toxicol. 2012;13.

17. Byrne JA, Grieve DJ, Cave AC, Shah AM. Oxidative stress and heart failure. Arch Mal Coeur. 2003;96:214-21.

18. Haed S, Barshack I, Luboshits G, Wexler D, Deutsch V, Keren G, et al. Erythropoietin improves myocardial performance in doxorubicin-induced Cardiomyopathy. Eur. Heart J. 2006;27:1876-83.

19. Yilmaz S, Atessahin A, Sahna E, Karahan I, Ozer S. Protective effect of lycopene on adriamycin-induced cardiotoxicity and nephrotoxicity. Toxicology. 2006;218:164-71.

20. Akinmoladun ACB, Ibukun EO, Afor E, Akinrinlola, BL, Onibon TR, Akinboboye AO, et al. Chemical constituents and antioxidant activity of Alstonia boonei. Afr. J. Biotechnol. 2007;6(10):1197-201.

21. Krishnamurthy B, Rani N, Bharti S, Golechha M, Bhatia J, Nag TC, et al. Febuxostat ameliorates doxorubicin-induced cardio toxicity in rats Chem Biol Interact. 2015;237:96-103.

22. Sikdar M, Dutta U. Tradional phytotherapy among the nath people of Assam. Ethno-Med. 2008;2:39-45.

23. Subburaman S, Ganesan K, Ramachandran M. Protective role of naringenin against doxorubicininduced cardio toxicity in a rat model: histopathology and mRNA expression profile studies. Food Chem Toxicol. 2010;48(5):1178-84.

24. Suchalatha S, Devi SCS. Protective effect of terminalia chebula against experimental myocardial injury induced by isoproterenol. Indian Biol. 2004;42:174-8.

25. Panda VS, Naik SR. Cardioprotective activity of ginkgo biloba phytosomes in isoproterenol induced myocardial necrosis in rats: a biochemical and histoarchitectural evaluation. Exp Toxicol Pathol. 2008;60:397-404.

26. Farvin KHS, Anandan R, Kumar SH, Shiny KS, Sanka TV, Thankappan TK. Effect of squalene on tissue defense system in isoproterenol-induced myocardial infarction in rats. Pharmacol Res. 2004;50:231-36.

27. Garba IH, Ubom GA. Total serum lactate dehydrogenase activity in acute Plasmodium falciparum malaria infection. Singapore Med J. 2005;46:632-4.

28. Dewar HA, Rowell NR, Smith AJ. Serum glutamic oxaloacetic transaminase in acute myocardial infarction. Brt Med J.1958;8:1121-5.

Cite this article as: Varshney $\mathrm{P}$, Vishwakarma $\mathrm{P}$, Sharma M, Saini M, Bhatt S, Singh G, et al. Cardioprotective effect of solanum nigrum against doxorubicin induced cardiotoxicity-an experimental study. Int J Basic Clin Pharmacol 2016:5:748-53. 